Published by Al-Nahrain College of Medicine P-ISSN 1681-6579

E-ISSN 2224-4719

Email: iraqijms@colmed-alnahrain.edu.iq http://www.colmed-alnahrain.edu.iq http://www.iraqijms.net

\title{
Ductectasia of the Breast; an Experience with Hadfield Operation (Radical Excision of the Subareolar Duct System)
}

\author{
Taqi S. Atiyah FICMS \\ Dept. of Surgery, College of Medicine/Al-Nahrain University, Baghdad, Iraq
}

\begin{abstract}
Background
\end{abstract}

Objective

Methods

Results

Conclusion

Keywords

Citation

Ductectasia of the breast is a benign condition. It is characterized by dilatation of the mammary ducts, which is often associated with periductal inflammation. Recurrent sepsis is often resistant to non-operative management. Furthermore, it can be very difficult to exclude malignancy.

To evaluate the significance of Hadfield operation (radical excision of major mammary ducts) in treatment of ductectasia and in detecting coexistent early carcinoma of the breast that cannot be visualized by ultrasound and mammography.

A Prospective study in Al-Imamein Al-Kadhimein Medical City for female patients with ductectasia of the breast over the period from April 2007 to April 2015. Ultrasound was done for all patients to prove the diagnosis and to exclude any suspicious mass. Mammography was done for patients above 40 years old. Patients with breast mass diagnosed clinically or by investigations were excluded from the study. Patients were divided into two groups according to the type of treatment; (Group A) patients were treated conservatively by antibiotics and analgesia, and (Group B) patients were treated surgically by radical excision of the major mammary ducts (Hadfield operation). Follow up of all patients for at least one year.

Over eight years of the study, the total number was 720 female patients, their age ranges from $21-$ 55 years with mean age ( $33 \pm 48$ year). Group A includes 614 ( $85.28 \%)$ patients, all of them were still complains of nipple discharge and not cured. Group B includes 106 (14.72\%) patients all of them were cured from nipple discharge. One patient in Group B accidentally found to have ductal carcinoma in situ of the breast which was not visualized by preoperative ultrasound or by mammography.

Conservative management of ductectasia of the breast does not relief symptoms of nipple discharge, while surgical excision of major mammary ducts relief symptoms of nipple discharge. Coexistence of breast carcinoma in situ (which was not appeared by preoperative ultrasound and mammography of the breast) in specimen of excised mammary ducts is an interested finding.

Ductectasia of the breast; Hadfield operation; early breast carcinoma

Taqi S. Atiyah. Ductectasia of the breast; an experience with hadfield operation (radical excision of the subareolar duct system). Iraqi JMS. 2017; Vol. 15(1): 20-26. doi: 10.22578/IJMS.15.1.4

\section{Introduction}

$\mathrm{D}$ uctectasia of the breast is a benign condition associated with periareolar sepsis (periductal mastitis). It is characterized by dilation of major ducts in the subareolar region. The ducts contain eosinophilic granular secretions and foamy histiocytes ${ }^{(1)}$. Ductectasia affects primarily middle-aged to elderly women but can occasionally occur in children (2). Nipple discharge is the third most common reason for presentation to a breast clinic (3). In cases of ductectasia, the dilated lactiferous ducts are filled with a stagnant brown or green secretion which may discharge. These fluids then set up an irritant reaction in surrounding tissue 
leading to periductal mastitis or even abscess and fistula formation. Sometimes the discharge may be blood stained (4).

An alternative theory suggests that periductal inflammation is the primary condition and, indeed, anaerobic bacterial infection is found in some cases. Nipple discharge (of any color), a subareolar mass, abscess, mammary duct fistula and/or nipple retraction are the most common symptoms. Conservative management of ductectasia is by antibiotic, the most appropriate agents being co-amoxiclav or flucloxacillin and metronidazole. Fibrosis eventually develops, which may cause slit-like nipple retraction. In some cases, a chronic indurated mass forms beneath the areola, which mimics a carcinoma. Recurrent sepsis is often resistant to non-operative intervention. Persistent or recurrent cases of ductectasia are managed with surgical excision of the ducts below the nipple. A focused excision is preferable, as there are lower rates of seroma formation, nipple numbness and nipple inversion (5).

Furthermore, it can be very difficult to exclude malignancy and ultrasound of the breast and mammography may still miss a small proportion of cases of carcinoma of the breast. A mammogram should be performed whenever complicated, malignant and uncommon forms of mastitis are suspected (6). The aim of the study was to evaluate the methods of the management of patients with ductectasia of the breast

\section{Methods}

After ethical approval of the study by Institution Review Board in the College of Medicine, Al-Nahrain University, a prospective cross sectional study performed in Al-Imamein Al-Kadhimein Medical City, Breast Consultation Clinic, for female patients complained of nipple discharge and non-cyclical mastalgia (and were diagnosed as ductectasia of the breast by ultrasound) over the period from April 2007April 2015.
Exclusion criteria include; patients with palpable breast mass, or had radiological mass by ultrasound or mammography, patients with bloody nipple discharge, and patients with coexistent breast carcinoma; all those patients were excluded from the study because they were already managed by the protocol of breast mass, or bloody nipple discharge.

Inclusion criteria include patients presented with non-cyclic mastalgia and nipple discharge (other than bloody discharge) and were proved to have ductectasia of the breast by ultrasound; with no other detectable breast diseases by clinical examination or radiological investigations.

Proper history and physical examination was done for every patient. Patients were presented with non-cyclic mastalgia with nipple discharge of different colors (brown or greenish discharge). Ultrasound of the breast was done for all patients to prove the diagnosis and to exclude any suspicious mass or other disease of the breast. Mammography was done for older patients for the same reason. Nipple discharge of all patients was sent for cytology to exclude malignancy and for culture and sensitively to choose appropriate antibiotics.

Patients were divided into two groups according to the type of treatment; (Group A) patients were treated conservatively by antibiotics, analgesia, reassurance and follow up; and (Group B) patients were treated surgically by radical excision of the subareolar duct system (Hadfield Operation) after explaining for them the procedure, its possible complications, and written consent was taken from them; all the ducts under the nipple and areola are excised and it is, therefore, obviously not advised if future breastfeeding is anticipated; the excised major mammary ducts were sent for histopathological examination.

One patient with incidental finding of ductal carcinoma in situ (which is not shown by preoperative ultrasound or preoperative mammography and was an accidental histopathological result) was submitted to simple mastectomy. 
All the patients were followed up for at least one year and were monitored for, nipple discharge, non-cyclic mastalgia, and complications of surgery for those patients who underwent surgery.

\section{Results}

Over eight years, the total number was 720 female patients; their age ranges from 21-55 years with mean age ( $33 \pm 48$ year). (Group A) patients, who were treated conservatively by antibiotics and analgesia, include 614 (85.28\%) patients. (Group B) patients who were treated by surgical excision of the major mammary ducts (Hadfield operation) include 106(14.72\%) patients. Figure (1) shows the number of patients treated conservatively versus operative treatment (Hadfield operation). Cytological examination of the nipple discharge was negative for malignancy in all patients.

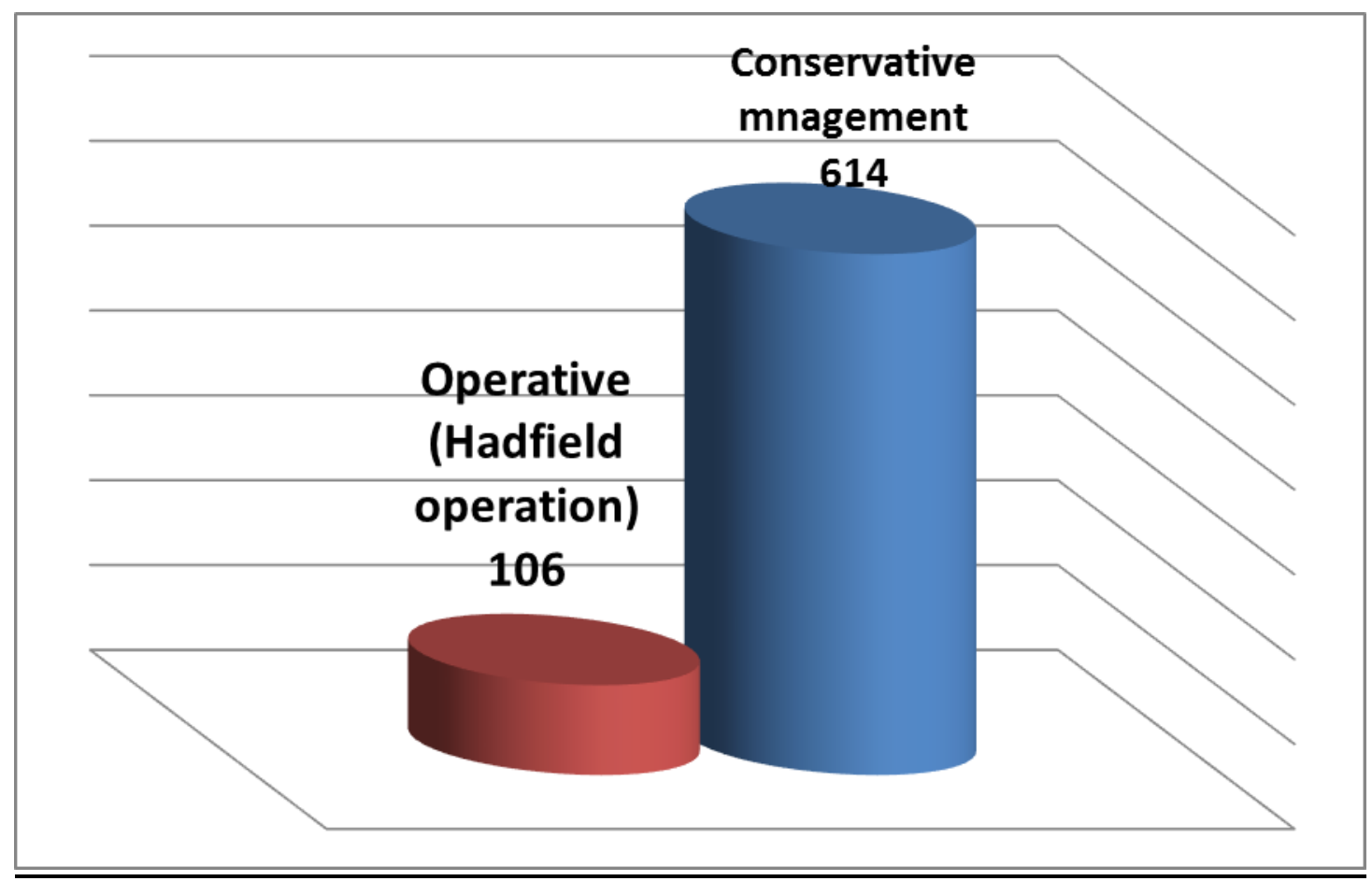

Figure 1. The number of patients treated conservatively versus operative treatment (Hadfield operation)

Operative findings of patients who underwent surgery shows dilatation of major mammary ducts in all patients in addition to that, some patients had other findings; 6 (5.66\%) patients had breast abscess that cause destruction of more than half of the breast tissue (due to neglected ductectasia); 4 (3.77\%) patients had toothpaste like material that involve the whole breast tissue even its periphery (thickened secretions that involve the minor ducts). One (0.94\%) patient unexpectedly found that her histopathological examination was ductal carcinoma in situ, which was not appeared preoperatively (she had no palpable mass on clinical examination and her preoperative investigations was normal ultrasound and normal mammography), simple mastectomy was done for this patient after receiving her histopathological result. Table (1) shows the unexpected operative findings in addition to dilated major mammary ducts.

Follow up of all patients for at least one year shows that Group A patients still complain of nipple discharge and breast discomfort in spite of treatment with antibiotics and analgesia. While Group B patients who were treated by 
surgical excision of major mammary ducts (Hadfield operation); 106 (100\%) patients got complete relief of nipple discharge which is significant $(P<0.05)$; and 95 (89.62\%) patients had got complete relief of their pain and discomfort of the breast and had no complications which is also significant $(\mathrm{P}<$ $0.05)$; while 11 (10.38\%) patients still have, but mild discomfort of the breast. Table (2) shows symptoms of patients after one year follow up.

Table 1. Additional Operative findings apart from dilated major mammary ducts

\begin{tabular}{lc}
\hline Additional operative findings (other than ductectasia) & $\begin{array}{c}\text { No. of patients } \\
\text { (\%) }\end{array}$ \\
\hline $\begin{array}{l}\text { Toothpaste like material that involve the whole breast } \\
\text { Breast abscess that cause destruction of more than half of the } \\
\text { breast tissue }\end{array}$ & $4(3.77 \%)$ \\
$\begin{array}{l}\text { Coexistent carcinoma in situ that was not visualized preoperatively } \\
\text { (normal U/S and mammography preoperatively) }\end{array}$ & $1(5.66 \%)$ \\
\hline
\end{tabular}

Table 2. Symptoms of patients after one year follow up; conservative treatment versus surgical treatment

\begin{tabular}{cccccc}
\hline \multirow{2}{*}{ Symptoms } & \multicolumn{2}{c}{ Conservative treatment } & \multicolumn{2}{c}{$\begin{array}{c}\text { Surgical treatment } \\
\text { (Hadfield operation) }\end{array}$} & Significance \\
\cline { 2 - 5 } & $\begin{array}{c}\text { After } \\
\text { treatment }\end{array}$ & $\begin{array}{c}\text { Before } \\
\text { treatment }\end{array}$ & $\begin{array}{c}\text { After } \\
\text { treatment }\end{array}$ & $\begin{array}{c}\text { Before } \\
\text { treatment }\end{array}$ & level \\
\hline $\begin{array}{c}\text { Nipple } \\
\text { discharge } \\
\begin{array}{c}\text { Pain and } \\
\text { discomfort }\end{array}\end{array}$ & 614 & $614(100 \%)$ & 106 & None & $\mathrm{P}<0.05$ \\
\hline
\end{tabular}

Complications of surgery were, 11 (10.38\%) patients had experienced altered nipple sensation and paraesthesia; 5 (4.71\%) patients had mild deformity of the nipple. Table (3) shows the complications of surgery.

Table 3. Complication of surgery (Hadfield operation)

\begin{tabular}{cc}
\hline Complications of Surgery & No. of patients (\%) \\
\hline Altered nipple sensation and paraesthesia & $11(10.38 \%)$ \\
Deformity of the nipple & $5(4.71 \%)$ \\
\hline
\end{tabular}

\section{Discussion}

Nipple discharge is the third most common reason for presentation to a breast clinic (3). Conservative management of patients with ductectasia of the breast with antibiotics does not cure the condition, and the patients were still complaining of nipple discharge and non- cyclic mastalgia. Ductectasia for prolonged time may lead to advanced destruction of the breast tissue by sepsis.

Surgical excision of major mammary ducts (Hadfield operation) relief the patient's symptoms of nipple discharge $(P<0.05)$, and non-cyclic mastalgia. In the cohort of patients 
operated upon; Hadfield operation was safe, simple and without serious complications other than occasional cases of altered nipple sensation, and deformity of the nipple.

Unfortunately, one patient's histopathological report was carcinoma in situ, which was not shown by clinical examination or by radiological examination (ultrasound and mammography). This patient was submitted to simple mastectomy.

Ultrasound of the breast remains operator dependent. Normal mammogram does not exclude the presence of carcinoma. Early breast carcinoma may not present as a welldefined mass that can be detected by radiological examination. In total, 5 per cent of breast cancers are missed by population-based mammographic screening programs, even in retrospect such carcinomas are not apparent (7).

For these reasons, and when breastfeeding is not anticipated, patients who were bothered by nipple discharge, may get benefit by surgical excision of major lactiferous ducts (Hadfield operation) because, beside they get rid of nipple discharge and relief their symptoms without long term courses of antibiotics; there may be a coexistent carcinoma in situ which had not been detected by triple assessment of the breast and so get proper early management and prevent serious events if delayed; as it was found in one (0.94\%) of the patients with ductectasia in this study who had normal preoperative ultrasound and mammography of the breast and treated surgically by excision of the major mammary ducts (Hadfield operation) and incidentally found to have ductal carcinoma in situ, for which simple mastectomy was performed.

Ductal imaging by ductography is helpful in detecting ductal carcinoma of the breast but it is non-specific ${ }^{(8)}$. Ductography has a highpositive predictive value in the diagnosis of intra ductal lesions, papilloma and carcinoma; however, it has a low sensitivity and is painful (3).
Breast ductoscopy is an evolving technology. However, further studies are required to define its role more clearly, as there are still limitations in clinical practice (8-14). Magnetic resonance imaging (MRI) may play an adjunctive role, aiding in the differentiation of benign ductal abnormalities from malignant ones (15-18).

Although not a routine practice in the United Kingdom; a number of techniques have been used to determine the cause of nipple discharge, beyond the triple assessment. Nipple discharge cytology has a low sensitivity for the detection of breast cancer (19) and is unlikely to alter the management of patients with nipple discharge ${ }^{(20)}$.

Hadfield's procedure and microdochectomy are the most common techniques for the surgical treatment of patients with nipple discharge. Both techniques enable histopathological diagnosis and treatment of symptoms. Recognized side effects of these procedures include nipple deformity, necrosis, and periareolar anesthesia in some cases $(20 \%)$ (2123).

There are many advanced studies and investigations for early detection of breast carcinoma, but all the investigations carry a certain percentage of false negative results in detecting early breast carcinoma, even advanced investigations like MR imaging with different contrast materials are not $100 \%$ accurate in excluding early breast carcinoma (23-32) and this support the advice of this study treating older patients with ductectasia (when breastfeeding is not anticipated) by surgical excision of the major lactiferous ducts (Hadfield operation), in trial to find coexistent ductal carcinoma in situ that may not be detected by mammography nor by ultrasound study of the breast.

This study concluded that conservative management of ductectasia of the breast by antibiotics does not relief symptoms. When breastfeeding is not anticipated, patients who were bothered by nipple discharge due to ductectasia may get benefit by surgical excision 
of major lactiferous ducts (Hadfield operation) to relief their symptoms and to detect any coexistent carcinoma in situ which had not been detected by mammography and ultrasound.

\section{Acknowledgments}

None.

\section{Conflict of interest}

None.

\section{Funding}

Self-funding.

\section{References}

1. Guray $M$, Sahin $A A$. Benign breast diseases: classification, diagnosis, and management. Oncologist. 2006; 11(5) :435-49. doi: 10.1634/theoncologist.11-5-435.

2. McHoney M, Munro F, Mackinlay G. Mammary duct ectasia in children: report of a short series and review of the literature. Early Hum Dev. 2011; 87(8): 527-30. doi: 10.1016/j.earlhumdev.2011.04.005.

3. Goksel HA, Yagmurdur MC, Demirhan B, et al. Management strategies for patients with nipple discharge. Langenbecks Archiv Surg. 2005; 390(1): 52-8.

4. Hussain AN, Policarpio C, Vincent MT. Evaluating nipple discharge. Obstet Gynecol Surv. 2006; 61(4): 278-83.

5. Zervoudis $S$, latrakis $G$, Economides $P$, et al. Nipple discharge screening. Women's Health (Lond). 2010; 6(1): 135-51. doi: 10.2217/whe.09.81.

6. Kamal RM, Hamed ST, Salem DS. Classification of inflammatory breast disorders and step by step diagnosis. Breast J. 2009; 15(4): 367-80. doi: 10.1111/j.1524-4741.2009.00740.x.

7. Morakkabati-Spitz N, Leutner C, Schild H, et al. Diagnostic usefulness of segmental and linear enhancement in dynamic breast MRI. Eur Radiol. 2005; 15(9): 2010-7.

8. Hou MF, Tsai KB, Ou-Yang F, et al. Is a one-step operation for breast cancer patients presenting nipple discharge without palpable mass feasible? Breast. 2002; 11: 402-7.

9. Louie LD, Crowe JP, Dawson AE, et al. Identification of breast cancer in patients with pathologic nipple discharge: does ductoscopy predict malignancy? Am J Surg. 2006; 192(4): 530-3.

10. Escobar PF, Crowe JP, Matsunaga T, et al. The clinical applications of mammary ductoscopy. Am J Surg. 2006; 191(2): 211-5.

11. Dooley WC. Routine operative breast endoscopy for bloody nipple discharge. Ann Surg Oncol. 2002; 9(9): 920-3.
12. Denewer A, El-Etribi $K, \mathrm{Nada} N$, et al. The role and limitations of mammary ductoscope in management of pathologic nipple discharge. Breast J. 2008; 14(5): 442-9. doi: 10.1111/j.1524-4741.2008.00620.x.

13. Simpson JS, Connolly EM, Leong WL, et al. Mammary ductoscopy in the evaluation and treatment of pathologic nipple discharge: a Canadian experience. Can J Surg. 2009; 52(6): E245-8.

14. Kamali S, Bender O, Aydin MT, et al. Ductoscopy in the evaluation and management of nipple discharge. Ann Surg Oncol. 2010; 17(3): 778-83.

15. Dooley WC. Breast ductoscopy and the evolution of the intraductal approach to breast cancer. Breast. 2009; 15, supplement 1: S90-4. doi: 10.1111/j.15244741.2009.00799.x.

16. Hirose M, Otsuki N, Hayano D, et al. Multi-volume fusion imaging of $M R$ ductography and $M R$ mammography for patients with nipple discharge. Magn Reson Med Sci. 2006; 5(2): 105-12.

17. Tokuda Y, Kuriyama K, Nakamoto A, et al. Evaluation of suspicious nipple discharge by magnetic resonance mammography based on breast imaging reporting and data system magnetic resonance imaging descriptors. J Comput Assist Tomogr. 2009; 33(1): 5862. doi: 10.1097/RCT.0b013e3181671ad2.

18. Lorenzon M, Zuiani C, Linda A, et al. Magnetic resonance imaging in patients with nipple discharge: should we recommend it? Eur Radiol. 2011 May;21(5):899-907. doi: 10.1007/s00330-010-2009$y$.

19. Ballesio L, Maggi C, Savelli S, et al. Role of breast magnetic resonance imaging (MRI) in patients with unilateral nipple discharge: preliminary study. Radiol Med. 2008; 113(2): 249-64. doi: 10.1007/s11547008-0245-x.

20. Cabioglu N, Hunt KK, Singletary SE, et al. Surgical decision making and factors determining a diagnosis of breast carcinoma in women presenting with nipple discharge. J Am Coll Surg. 2003; 196(3): 354-64.

21. Tamaki $Y$, Akashi-Tanaka $S$, Ishida $T$, et al. 3D imaging of intraductal spread of breast cancer and its clinical application for navigation surgery. Breast Cancer. 2002; 9: 289-95.

22. Dixon JM. ABC of breast diseases. $4^{\text {th }}$ ed. UK: WileyBlackwell, BMJ Books. 1994.

23. Orel SG, Schnall. MR imaging of the breast for the detection, diagnosis, and staging of breast cancer. Radiology. 2001; 220(1): 13-30.

24. Morris EA. Review of breast MRI: indications and limitations. In: Miller WT, Berg WA. (eds.) Seminars in roentgenology. Vol. 36. Breast imaging. Philadelphia: Saunders, 2001: p. 226-37.

25. Satake H, Shimamoto K, Sawaki A, et al. Role of ultrasonography in the detection of intraductal spread of breast cancer: correlation with pathologic findings, mammography and MR imaging. Eur Radiol. 2000; 10: 1726-32.

26. Uematsu T, Sano M, Homma $K$, et al. Comparison between high-resolution helical CT and pathology in breast examination. Acta Radiol. 2002; 43: 385-90. 
27. Nakahara H, Namba K, Fukami A, et al. Threedimensional MR imaging of mammographically detected suspicious microcalcifications. Breast Cancer. 2001; 8: 116-24.

28. Lindfors KK, Boone JM, Nelson TR, et al. Dedicated breast CT: initial clinical experience. Radiology. 2008; 246 (3): 725-33.

29. Newell D, Nie K, Chen JH, et al. Selection of diagnostic features on breast MRI to differentiate between malignant and benign lesions using computer-aided diagnosis: differences in lesions presenting as mass and non-mass like enhancement. Eur Radiol. 2010; 20(4): 771-81.

30. Chen SC, Carton AK, Albert M, et al. Initial clinical experience with contrast-enhanced digital breast tomosynthesis. Acad Radiol. 2007; 14(2): 229-38.
31. Perrone A, Lo Mele L, Sassi S, et al. MDCT of the breast. AJR Am J Roentgenol. 2008; 190(6): 1644-51. doi: 10.2214/AJR.07.3145.

32. Zhao $H, X u R$, Ouyang $Q$, et al. Contrast-enhanced ultrasound is helpful in the differentiation of malignant and benign breast lesions. Eur J Radiol. 2010; 73(2): 288-93. doi: 10.1016/j.ejrad.2009.05.043.

\section{E-mail: taqi.atyia@yahoo.com Received 4 ${ }^{\text {th }}$ Apr. 2016 Accepted 3 $3^{\text {rd }}$ Jan. 2017}

